Case Report

\title{
Clinical, Imaging and Histopathology of Angioleiomyoma of the Buccal Cheek
}

\author{
Mohammad Jafarian $\left(\mathbb{D},{ }^{1}\right.$ Fatemeh Mashhadi Abbas $\mathbb{D}^{2},{ }^{2}$ Mitra Ghazizadeh Ahsaie $\mathbb{D}^{\circ},{ }^{3}$ \\ and Homeira Saebnoori iD ${ }^{2}$ \\ ${ }^{1}$ Department of Oral and Maxillofacial Surgery, School of Dentistry, Shahid Beheshti University of Medical Sciences, Tehran, Iran \\ ${ }^{2}$ Department of Oral and Maxillofacial Pathology, School of Dentistry, Shahid Beheshti University of Medical Sciences, Tehran, Iran \\ ${ }^{3}$ Department of Oral and Maxillofacial Radiology, School of Dentistry, Shahid Beheshti University of Medical Sciences, Tehran, Iran
} Correspondence should be addressed to Mitra Ghazizadeh Ahsaie; mitraghazizadeh@gmail.com

Received 6 March 2021; Accepted 22 April 2021; Published 30 April 2021

Academic Editor: Giovanni Mergoni

Copyright (c) 2021 Mohammad Jafarian et al. This is an open access article distributed under the Creative Commons Attribution License, which permits unrestricted use, distribution, and reproduction in any medium, provided the original work is properly cited.

\begin{abstract}
Angioleiomyoma is a benign neoplasia originating from vascular smooth muscle and very uncommon in the oral cavity. In this report, we present a rare case of angioleiomyoma in oral cavity in a 46-year-old female buccal cheek and discuss the clinical, histological, and immunohistochemical characteristics. As the treatment of choice is the complete excision, the lesion was excised under local anesthesia with no further complications. In addition, a brief update on other reported cases of angiomyoma in the oral cavity is further discussed.
\end{abstract}

\section{Introduction}

Angiomyoma or angioleiomyoma (also known as vascular leiomyoma) are benign neoplasms originating from vascular smooth muscle $[1,2]$. Histologically, there are subgroups in three categories: solid, venous, and cavernous [3]. They commonly occur in the extremities and female genital tract and rarely in the oral cavity $[4,5]$. The most common site in the oral cavity is in the lips [1]. Other reported sites were the palate, tongue, cheek, gingiva, retromolar area, and submandibular triangle [2, 6-10]. Although the etiology is still unclear, previous studies report trauma or spontaneous development as the causes of origin in oral cavity $[10,11]$. The lesion is most often detected in adults of 30 to 50 years old [3]. Clinically, it usually presents as a slow growing, painless nodule or mass of variable size; however, pain has also been reported [12]. The final treatment and diagnosis is based on surgical excision and hematoxylin and eosin (H\&E) staining and immune-histochemical (IHC) assessments [1]. In this report, a rare case of angioleiomyoma in the cheek along with a complete imaging assessment including color Doppler ultrasonography, computed tomography (CT), and magnetic resonance imaging (MRI) with an update on the literature is presented.

\section{Case Report}

A 46-year-old female was referred to a private clinic of an Oral and Maxillofacial Surgeon with complaint of a painless swelling in the right side of her cheek since 6 years ago. The swelling was initially small in size and slowly enlarged, although the patients faced no tenderness in the area. The patient had diabetes mellitus and anemia. In addition, no history of previous trauma to the area was present. Extraoral examination showed no asymmetry or marked expansion on the right cheek. On intraoral examination, no clinically visible lesion was detected. The mucosa was intact with no color change. When the area was palpated, a firm, compressible solid mass was detected with moderate attachment to the adjacent tissues. The estimated size of the lesion was $1.5 * 1$ $\mathrm{cm}$, and the approximate diameter was $1.5 \mathrm{~cm}$. No pulsation or bruit was present. The patient had previously visited and had prior imaging including Doppler ultrasonography, multidetector computed tomography (MDCT), and MRI. The 


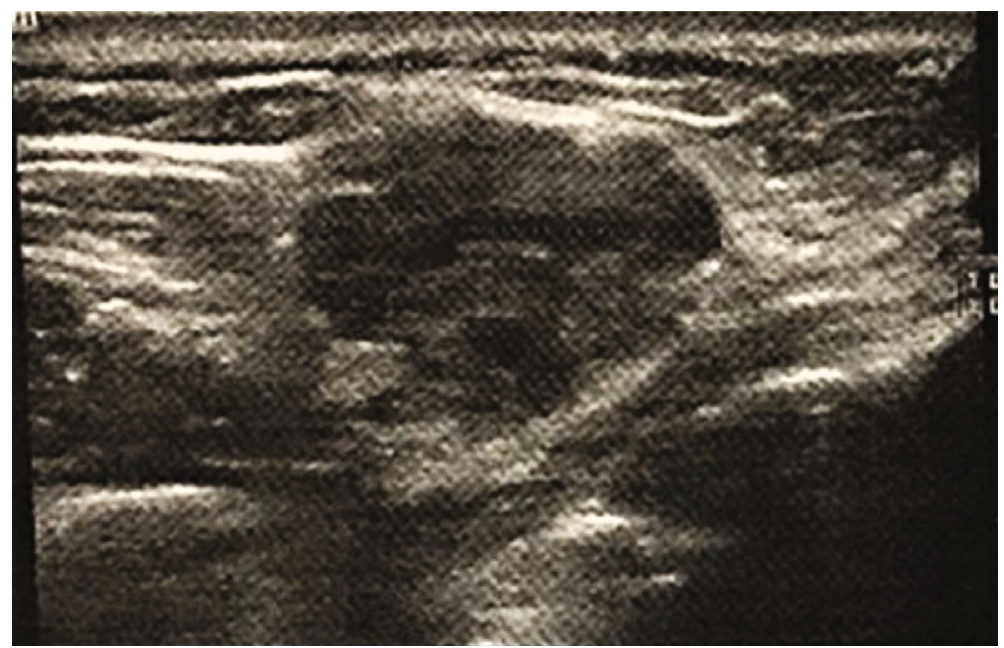

FIGURE 1: Ultrasonography shows a well-defined hypoechoic heterogenous mass lying between the skin and buccinator muscle.

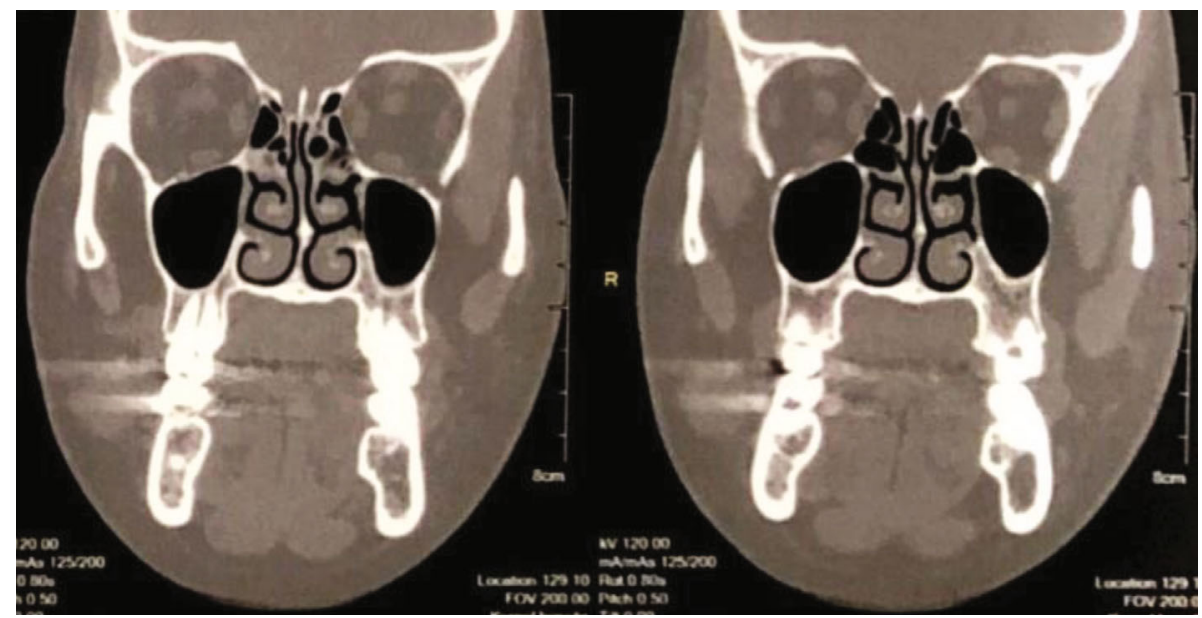

FIGURE 2: Coronal MDCT image shows a circular well-defined homogenous mass in the right buccal area.

results of ultrasonography indicated a well-defined hypoechoic heterogeneous mass lying beneath the skin measuring $13 * 18 \mathrm{~mm}$ (Figure 1). The lesion had moderate vascular flow. MDCT showed a circular well-defined homogenous mass over the buccinator muscle (Figure 2). The MRI T1 sequence showed a well-defined low signal mass between the buccinator muscle and buccal fat (Figure 3(a)). The MRI T2 sequence showed that the mass is homogenous and high signal (Figure 3(b)). A soft tissue mass was suspected, and an intraoral surgical excisional biopsy was planned. Upon obtaining consent, an excisional biopsy was performed under local anesthesia and incision was made on the buccal mucosa just over the palpated mass (Figure 4). The lesion was completely excised (Figure 5). H\&E staining histopathological examination demonstrated an encapsulated mass composed of fully developed cavernous angioma in a fibrous stroma and occasionally myxomatous change. The thin-wall blood vessels showed papillary projections to the lumen which some had become irregular, large in size, and even sinusoid in some areas (Figure 6(a)). The stroma contains immature spindle-shaped fibroblasts with a paralleling fasci- cle pattern next to the blood vessels (Figure 6(b)). The mixed inflammatory infiltration and hyalinized area intermixed with adipose tissue were also found. In the IHC staining analysis, the specimen was positive for both SMA (smooth muscle actin) (Figures 7(a) and 7(b)) and desmin (Figures 7(c) and $7(\mathrm{~d})$ ); however, the microscopic features in combination with IHC findings were consistent with angioleiomyoma diagnosis. A postoperative follow-up of the patient was uneventful. The area had healed with no complication, and no signs of recurrence were detected.

\section{Discussion}

Angioleiomyoma is a rare benign soft tissue neoplasm of oral cavity [7]. Although hormonal changes, trauma, and venous stasis are suggested as possible causes, the etiology is still unknown [5]. On our latest review of literature from year 2000 to 2020 using the PubMed Central search engine, 25 articles (32 cases) were retrieved (Table 1). The most common sites of oral angiomyomas were the lip $[2,4,12-15]$, cheek or buccal mucosa $[5,8,14,16-18]$, palate $[7,19-21]$, 


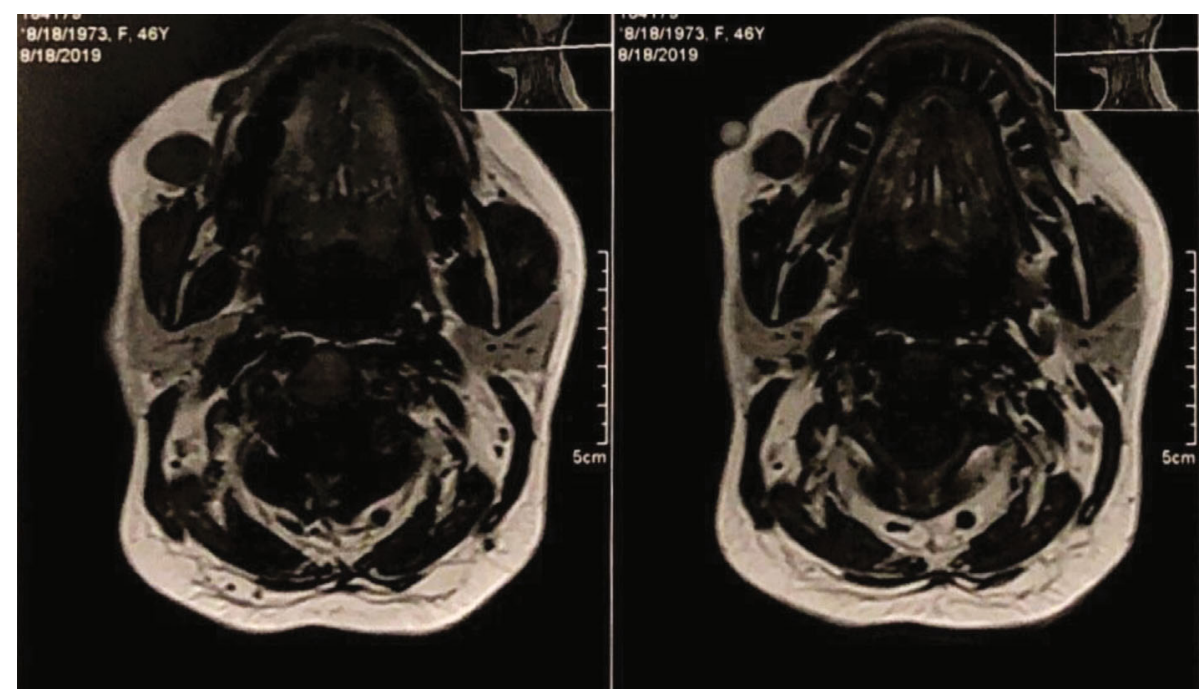

(a)

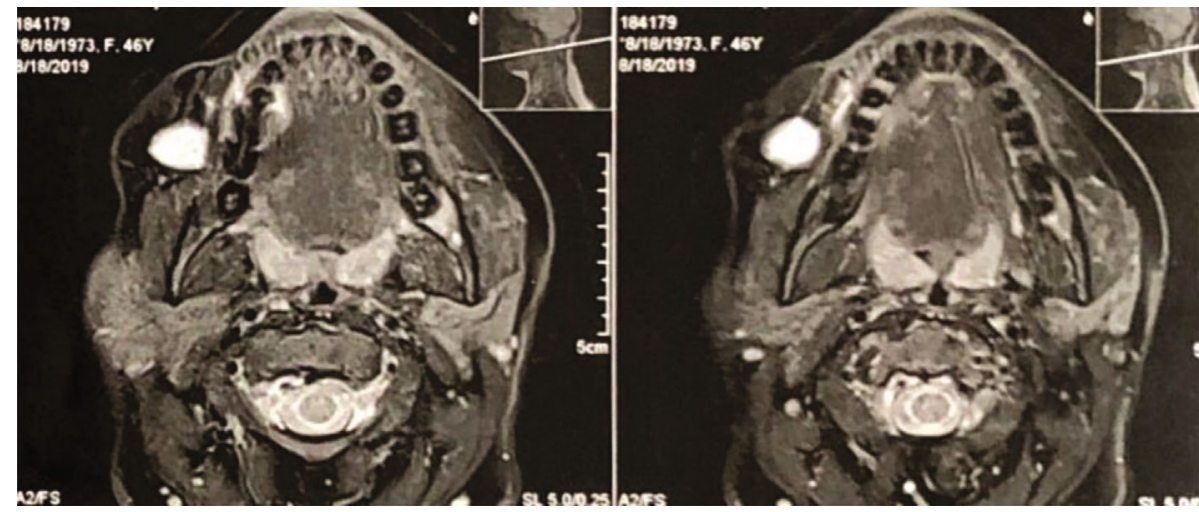

(b)

Figure 3: (a) Axial T1 MRI shows a low signal homogenous mass in the right lying over the buccinator muscle and under the skin. (b) Axial T2 MRI shows the lesion as high signal and homogenous.

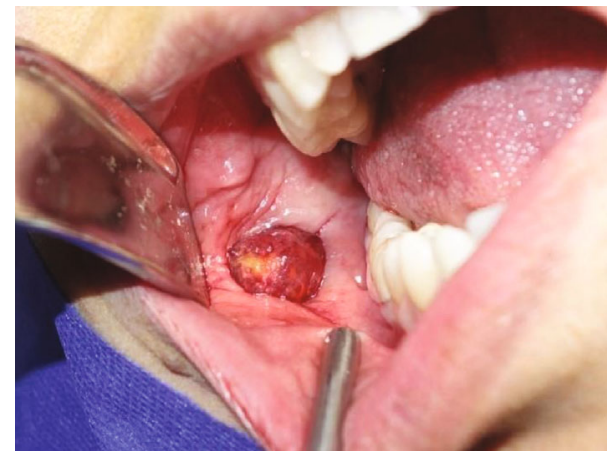

Figure 4: Intraoral incision on the buccal mucosa revealed a spherical lesion just underneath the buccinator muscle.

tongue $[6,22,23]$, and submandibular area $[9,11,24]$. The gingiva [10], mandible [2], retromolar area [2], and anterior maxillary labial fold [17] were each reported once among the studies. $73 \%$ of patients were male, and $27 \%$ were females, which is consistent with previous studies $[25,26]$. The mean age was $43 \pm 16.57$ years old (range 2 to 79 ). Only one study reported a congenital angiomyoma in the

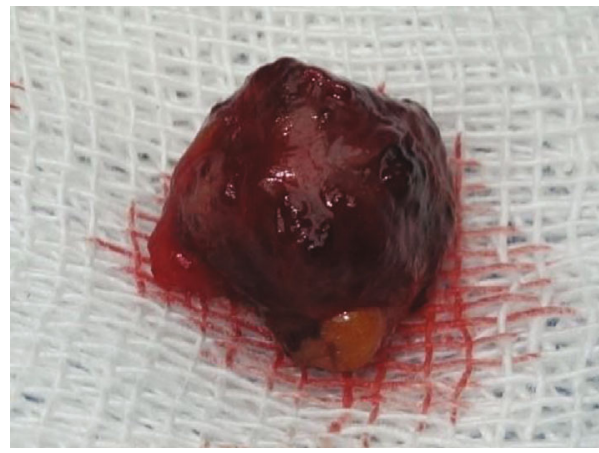

FIGURE 5: Image shows gross specimen, a spherical brown-gray firm tissue, measuring $1 \mathrm{~cm}$ in diameter.

tongue [3]. In all reviewed studies, the patient faced a painless swelling. Only three cases reported pain associated with the lesion [7, 21, 24].

Preoperative radiologic assessments varied among the studies, from no radiographic assessments and plain radiography to ultrasound, MRI, and CT evaluations. To our knowledge, this is the first case report of angioleiomyoma 


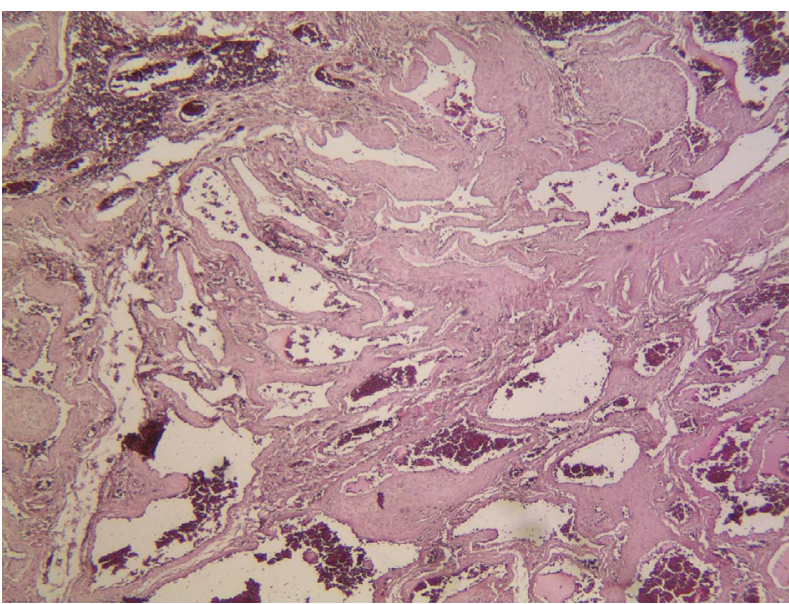

(a)

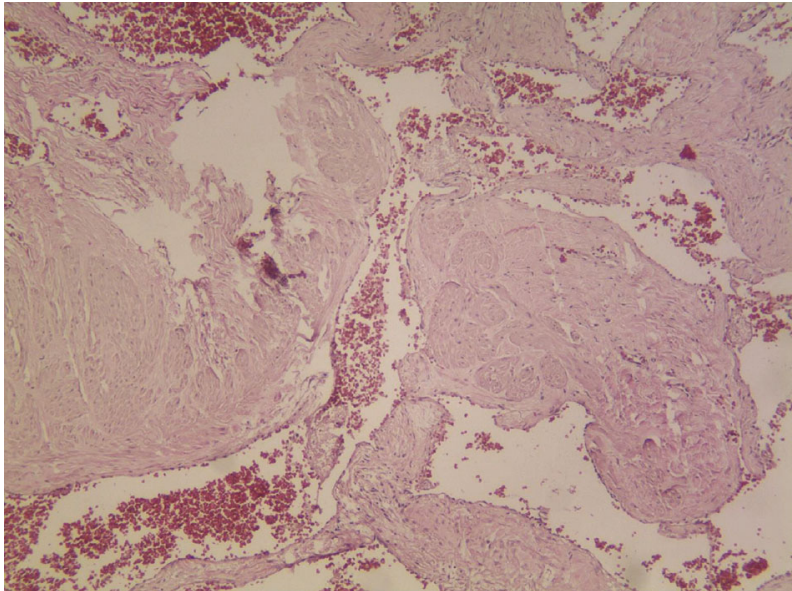

(b)

Figure 6: (a) Thin blood vessels with papillary projections in the fibrous stroma $(\times 40)$. (b) Paralleling pattern of fascicle and glomus cells around the blood vessels $(\times 100)$.

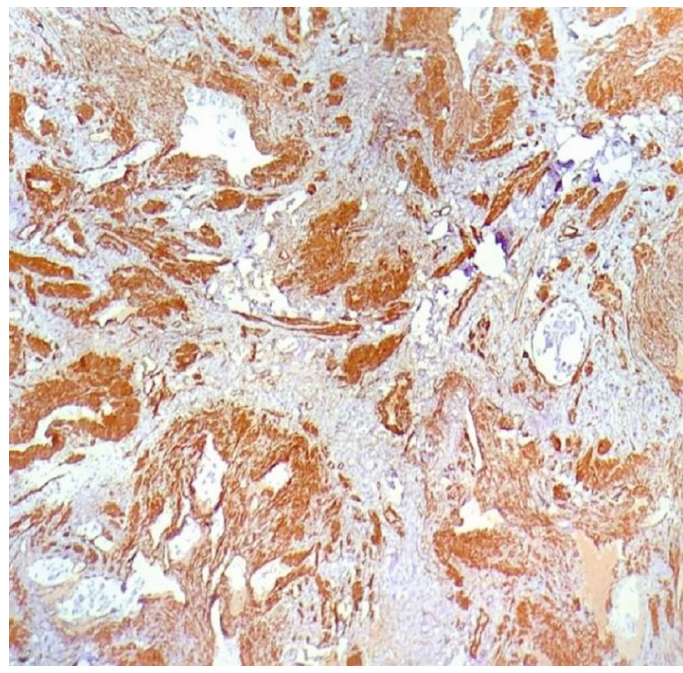

(a)

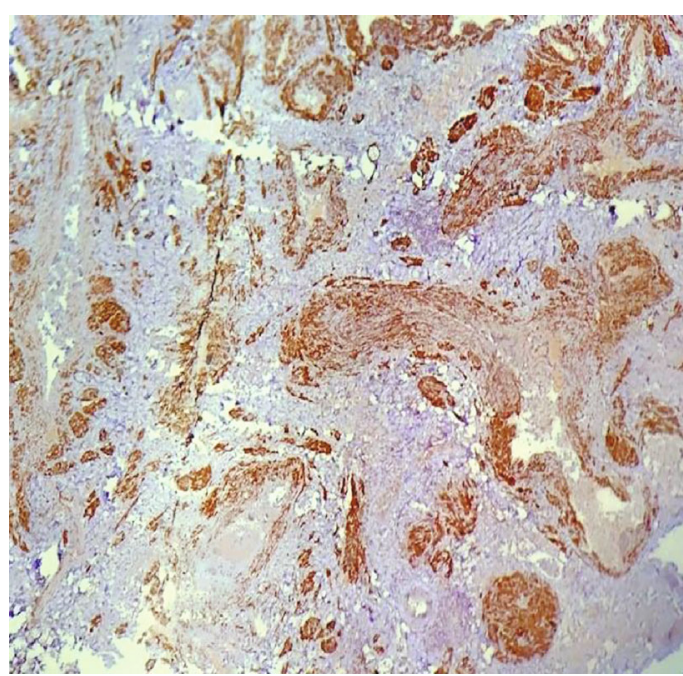

(c)

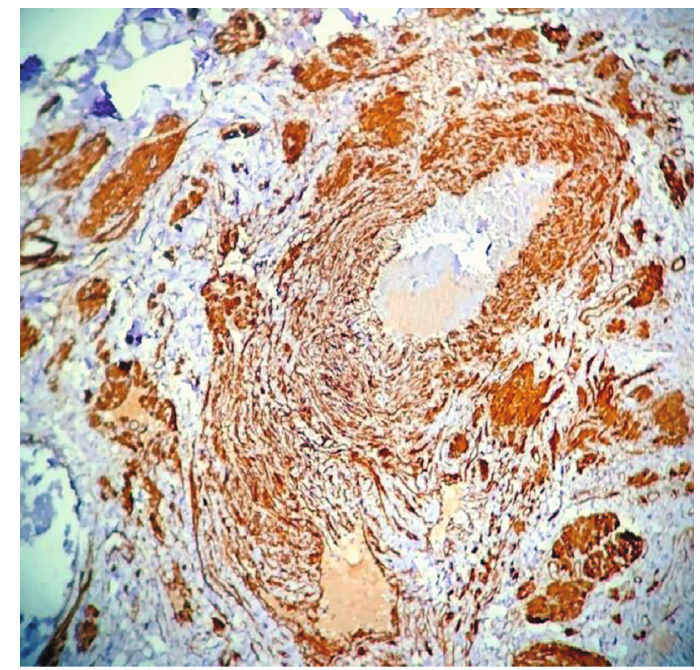

(b)

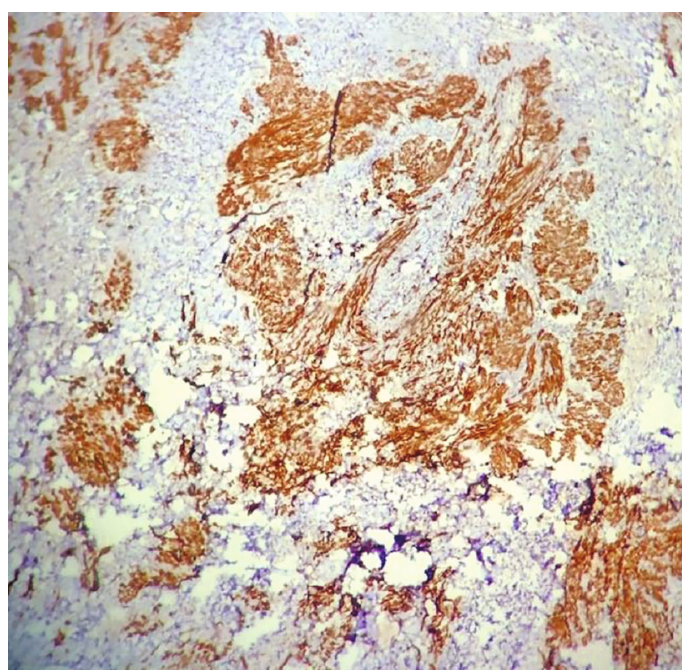

(d)

Figure 7: (a) $\times 40$ and (b) $\times 100$ positive IHC staining for SMA. (c) $\times 40$ and (d) $\times 100$ positive for desmin. 


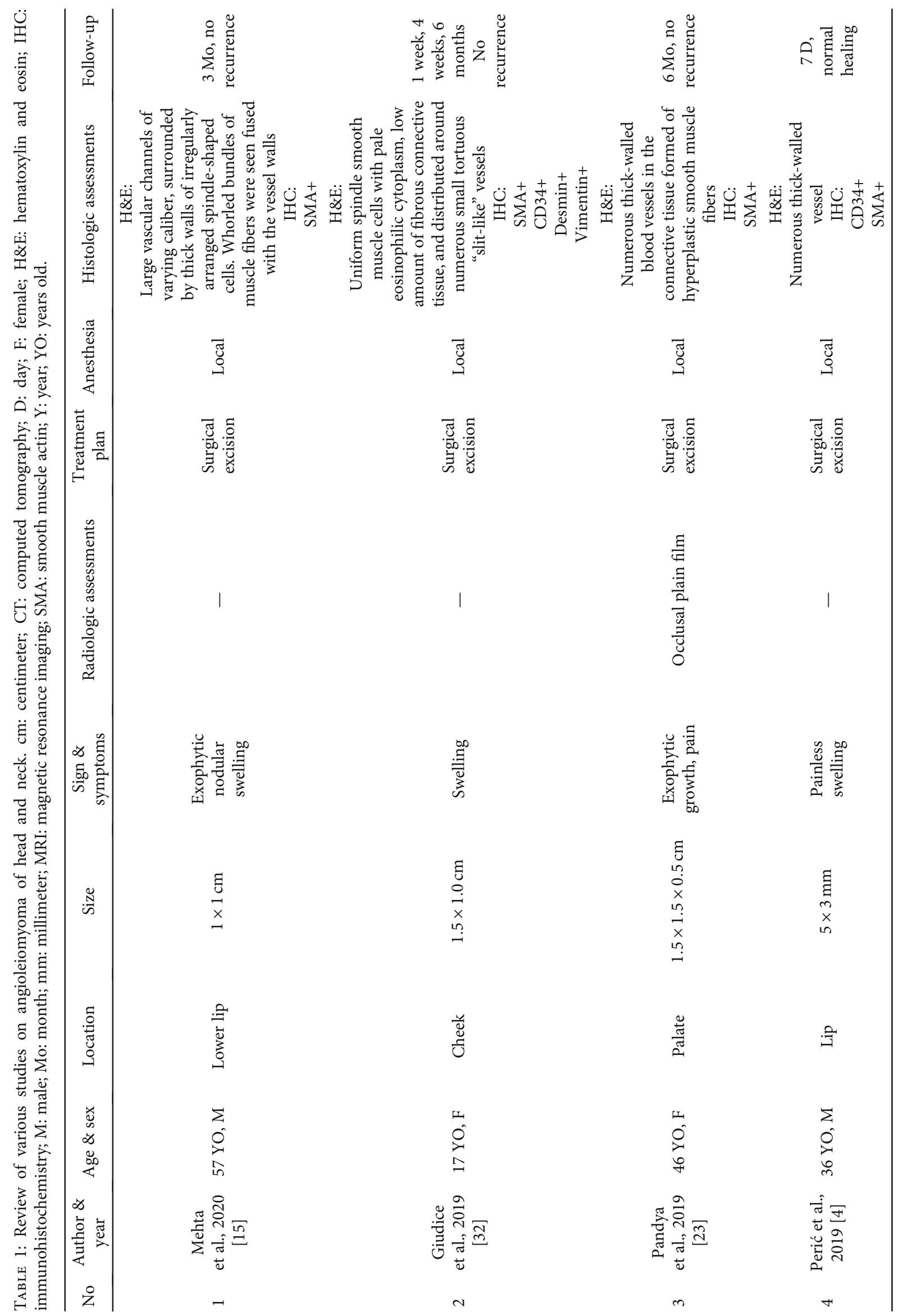




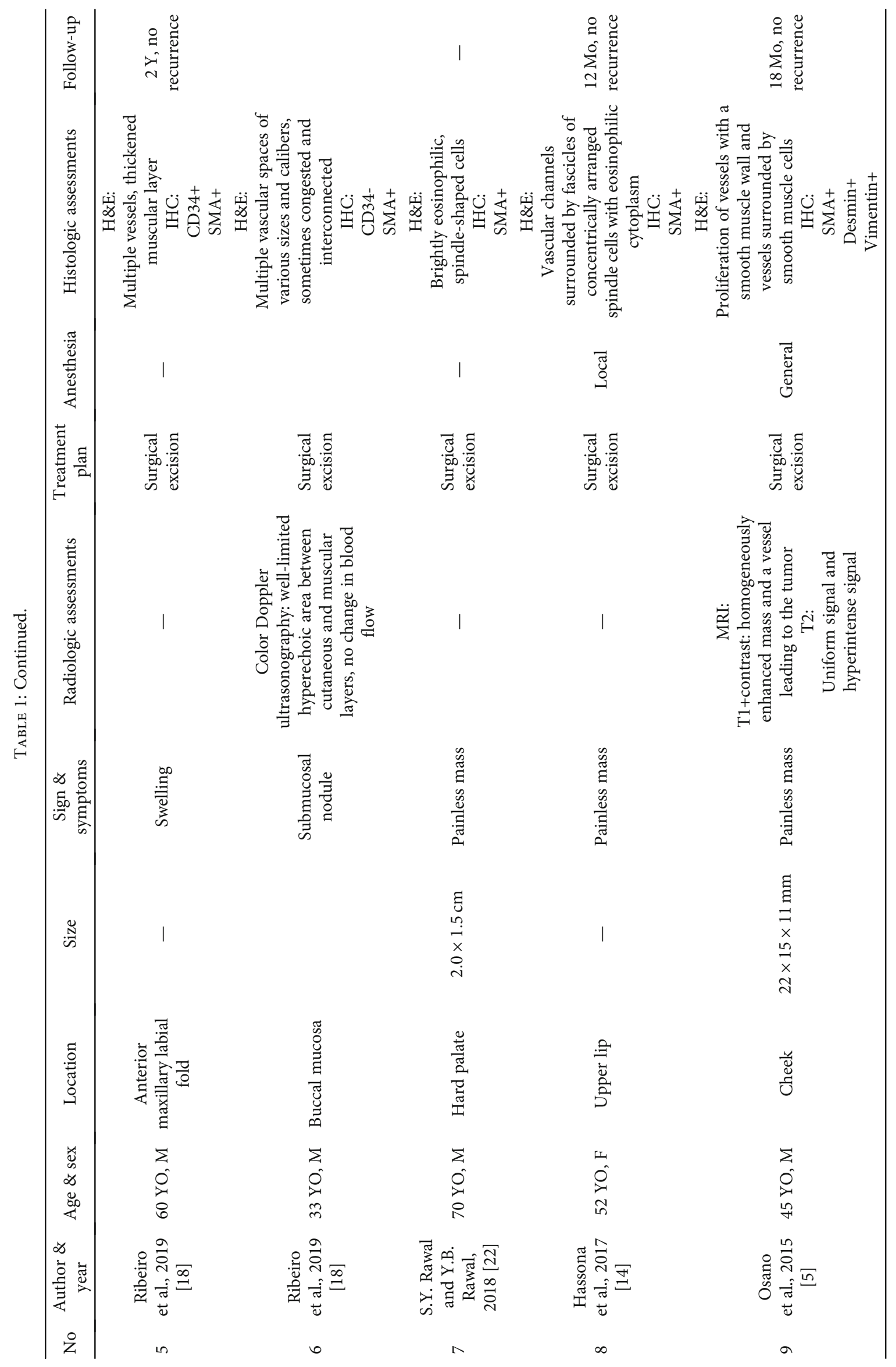




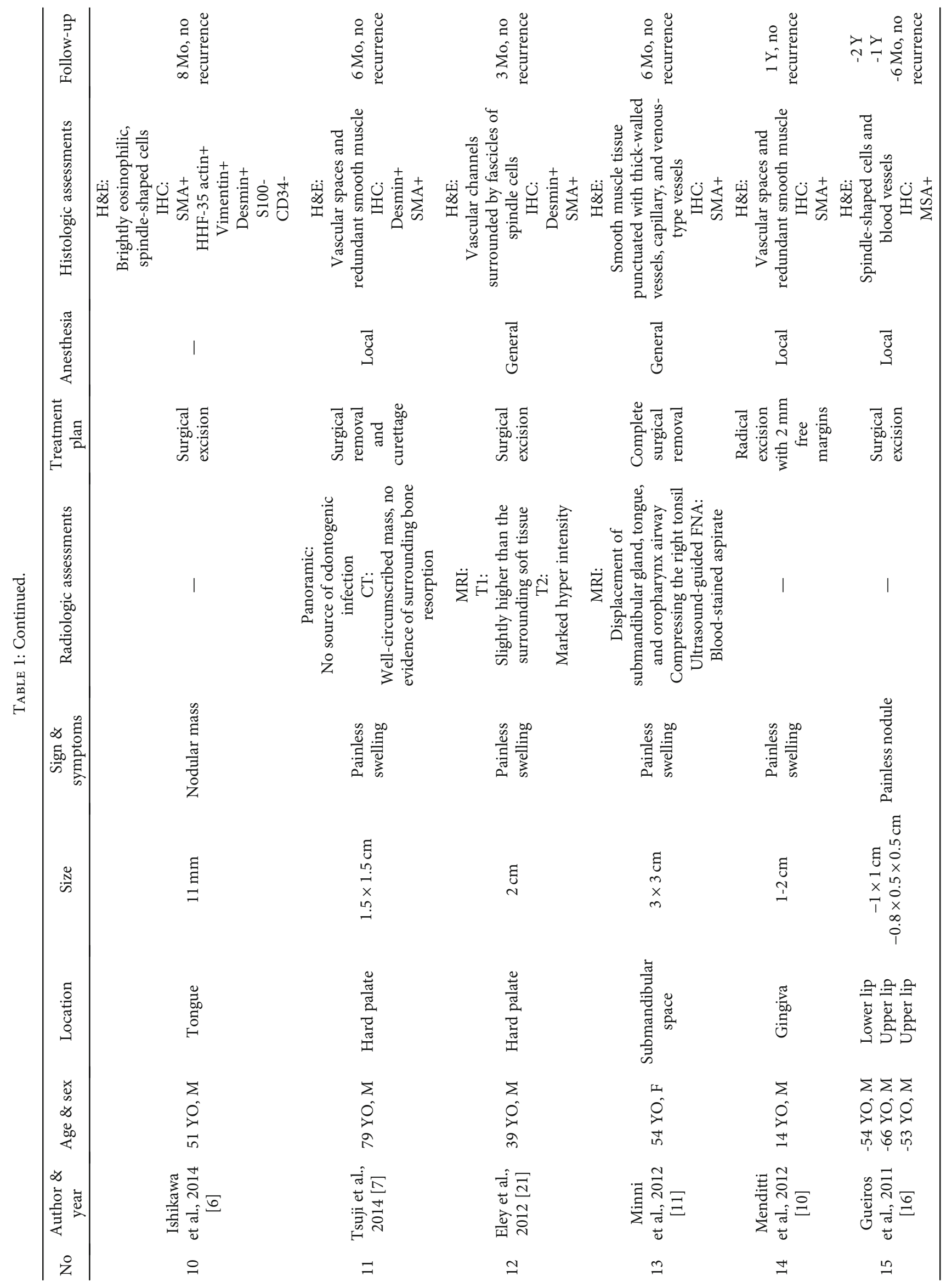




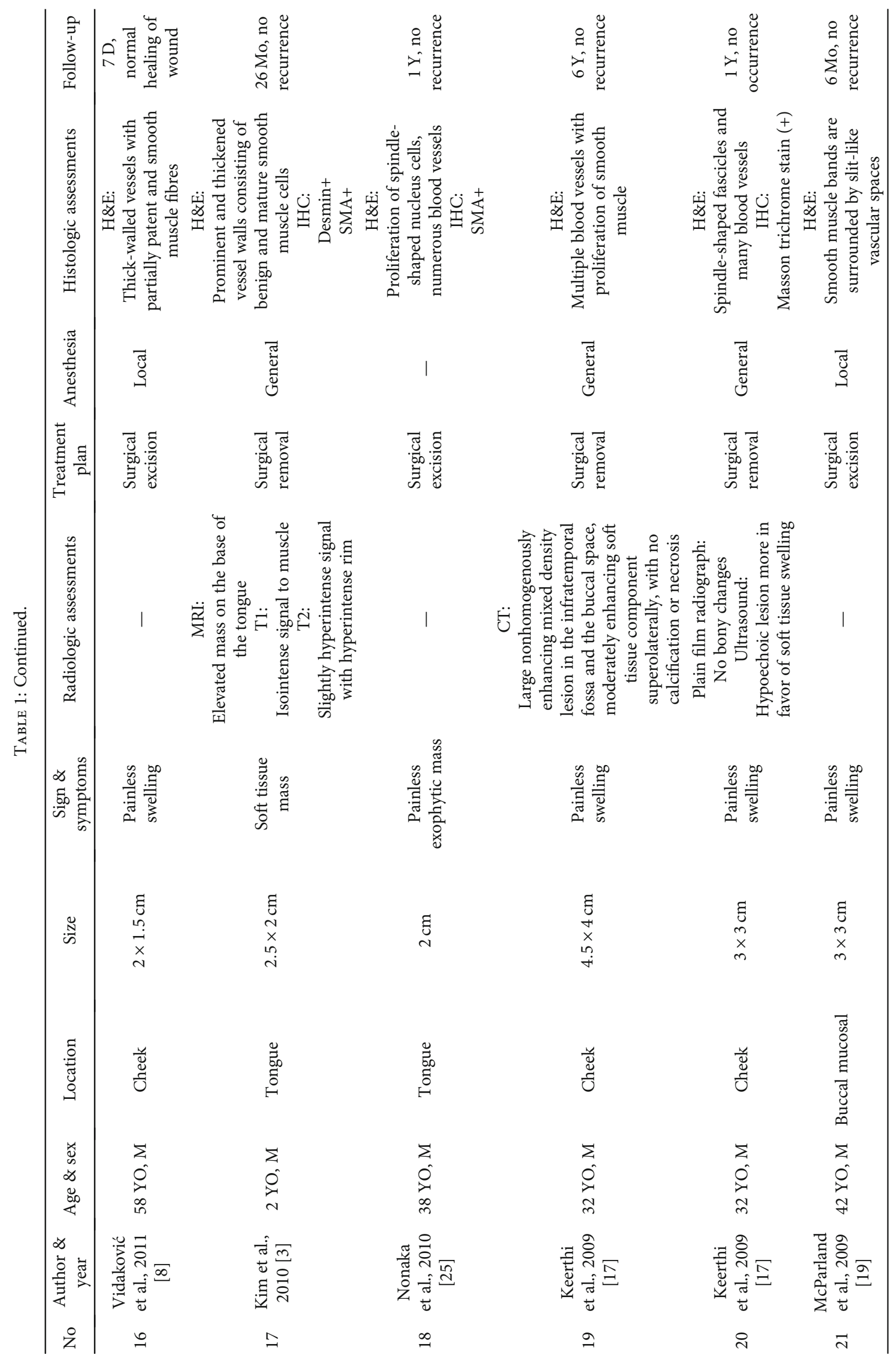




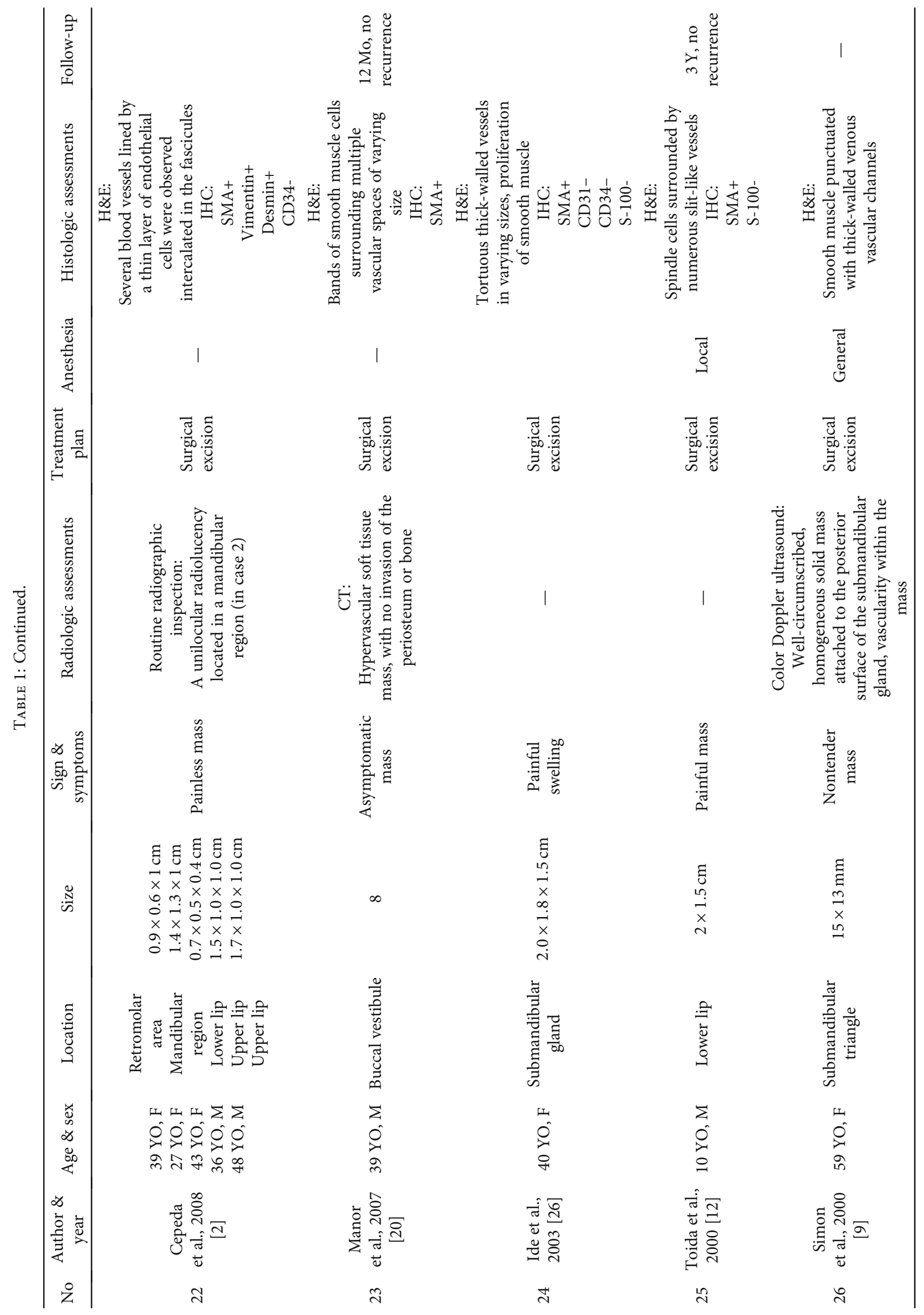


with a thorough imaging assessment including color Doppler sonography, MDCT, and MRI. The lesion was slightly heterogeneous hypoechoic mass with slight vascular flow in the color Doppler sonography; in addition, the T1-weighted and $\mathrm{T} 2$-weighted sequences were low and high, respectively. The high T2-weighted sequence may be seen in cysts, benign or low-grade minor salivary gland tumors, and rare hemangiomatous lesions [27]. In this case, differential diagnosis such as benign lesions of salivary gland origin was suggested in lower possibility because the lesion was located between the buccinator muscle and skin. Cystic lesions were also excluded as the sonography of the cyst is homogenous and unechoic [28]. Differential diagnosis may suggest other benign mesenchymal tumors such as fibroma, lipoma, and neurofibroma and vascular lesions including arteriovenous malformation, lymphangioma, and hemangioma. However, these lesions may have different radiographic and imaging characteristics. According to previous studies, the intraosseous angioleiomyomas are radiographically unilocular or multilocular radiolucent lesions. They can have either an ill-defined or a well-defined sclerotic border $[2,11]$.

In this case, $H \& E$ histologic examination showed a tumor consisting of thin- and thick-walled blood vessels in a background of smooth muscle proliferation. Having numerous blood vessels may pretend other benign vascular tumors such as hemangioma, hemangiopericytoma, hemangioendothelioma, vascular malformation, and other neurovascular hamartomas [29], but a definite examination could rule out these lesions because of the smooth muscle background. Immunohistochemically markers like SMA and MSA (muscle-specific actin) can be useful in identification of smooth muscle nature of the cellular stroma $[15,30,31]$. In the present study, IHC staining was positive for both desmin and SMA. Various IHC stainings were carried out among studies (Table 1) although SMA and desmin were the most frequent. Depending on the apparent features of the blood vessels, IHC staining of endothelial cell markers such as CD34 and CD31 was not recommended. Other differential diagnosis histopathologically is leiomyosarcoma if there were more cellular pleomorphism and mitosis figures. In addition to well circumscribing of this tumor, lacking of anaplasia and bizarre cells, fewer than 5 mitoses per 20 high-power fields could rule out sarcoma.

In all evaluated cases, the lesion was resected with an excisional biopsy under local or general anesthesia. There are no recurrences after resection.

\section{Conclusion}

In conclusion, we have reported a case of angioleiomyoma of the buccal cheek that resulted in a good outcome. Among various studies, the most common sites of oral angiomyomas were the lip $[2,4,12-15,32]$, cheek or buccal mucosa $[5,8$, $14,16-18]$, palate $[7,19-21]$, tongue $[6,22,23]$, and submandibular area $[9,11,24]$. Other areas such as the gingiva, mandible, retromolar area, and anterior maxillary labial fold were only reported once among studies $[2,10,17]$. Due to the benign nature of this lesion, the treatment is excisional biopsy and there have been no recurrences or complications reported so far [32].

\section{Data Availability}

The data used to support the findings of this study are available from the corresponding author upon request.

\section{Conflicts of Interest}

The authors declare no conflict of interest.

\section{References}

[1] J. Aitken-Saavedra, K.-D. da Silva, A.-C. Ana-Paula-Neutzling Gomes, U. Vasconcelos, A. Etges, and T.-G. Nóbrega, "Clinicopathologic and immunohistochemical characterization of 14 cases of angioleiomyomas in oral cavity," Medicina Oral, Patologia Oral y Cirugia Bucal, vol. 23, no. 5, p. e564, 2018.

[2] L. G. Cepeda, D. Q. Rivera, F. T. Rocha, E. Huerta, and E. Sanchez, "Vascular leiomyoma of the oral cavity. Clinical, histopathological and immunohistochemical characteristics. Presentation of five cases and review of the literature," Medicina Oral, Patología Oral y Cirugía Bucal, vol. 13, no. 8, pp. e483-e488, 2008.

[3] Y. Kim, Y. Jang, H. Pai, and S. Kim, "Congenital angiomyoma of the tongue: case report," Dentomaxillofacial Radiology, vol. 39, no. 7, pp. 446-448, 2010.

[4] B. Perić, B. Vidaković, N. Grgić, S. Manojlović, and H. Čavka, "Angiomyoma of the upper lip-case report and review of the literature," Acta Clinica Croatica, vol. 58, no. 1, pp. 183-186, 2019.

[5] H. Osano, Y. Ioka, R. Okamoto et al., "Angioleiomyoma of the cheek: a case report," Journal of Oral Science, vol. 57, no. 1, pp. 63-66, 2015.

[6] S. Ishikawa, S. Fuyama, T. Kobayashi, Y. Taira, A. Sugano, and M. Iino, "Angioleiomyoma of the tongue: a case report and review of the literature," Odontology, vol. 104, no. 1, pp. 119$122,2016$.

[7] T. Tsuji, K. Satoh, H. Nakano, and M. Kogo, "Clinical characteristics of angioleiomyoma of the hard palate: report of a case and an analysis of the reported cases," Journal of Oral and Maxillofacial Surgery, vol. 72, no. 5, pp. 920-926, 2014.

[8] B. Vidaković, A. Kotarac Knežević, S. Manojlović, and G. Knežević, "Angiomyoma-angioleiomyoma of the cheek," Collegium Antropologicum, vol. 35, no. 1, pp. 207-209, 2011.

[9] K.-H. W. Simon, A. Ahuja, J. Chow, and W.-K. K. Walter, "Angioleiomyoma in the submandibular region: an unusual tumor in an unusual site," Otolaryngology-Head and Neck Surgery, vol. 122, no. 1, pp. 144-145, 2000.

[10] D. Menditti, L. Laino, L. Nastri, U. Caruso, and P. Fiore, "Oral angioleiomyoma: a rare pathological entity," In Vivo, vol. 26, no. 1, pp. 161-163, 2012.

[11] A. Minni, A. De Carlo, R. Roukos, G. Illuminati, and B. Cerbelli, "Angioleiomyoma of the oral cavity extended to submandibular space; an unusual tumor in an unusual deepseated space: a case report," European Review for Medical and Pharmacological Sciences, vol. 16, no. 4, pp. 134-137, 2012.

[12] M. Toida, H. Koizumi, and K. Shimokawa, "Painful angiomyoma of the oral cavity: report of a case and review of the 
literature," Journal of Oral and Maxillofacial Surgery, vol. 58, no. 4, pp. 450-453, 2000.

[13] P. Ramesh, S. Annapureddy, F. Khan, and P. Sutaria, "Angioleiomyoma: a clinical, pathological and radiological review," International Journal of Clinical Practice, vol. 58, no. 6, pp. 587-591, 2004.

[14] Y. Hassona, F. Sawair, and C. Scully, "Angioleiomyoma of the upper lip,” Case Reports, vol. 2017, p. bcr-2016-219172., 2017.

[15] P. D. Mehta, N. Desai, K. Makwana, and Y. Patel, "Angioleiomyoma of the lower lip," Annals of Maxillofacial Surgery, vol. 10, no. 1, pp. 251-253, 2020.

[16] L.-A. Gueiros, M.-J. Romañach, A.-M. Pires-Soubhia, F.R. Pires, O. Paes-de-Almeida, and P.-A. Vargas, "Angioleiomyoma affecting the lips: report of 3 cases and review of the literature," Medicina Oral, Patología Oral y Cirugía Bucal, vol. 16, no. 4, pp. e482-e487, 2011.

[17] R. Keerthi, M. Nanjappa, S. S. Deora, and S. Kumaraswamy, "Angioleiomyoma of cheek: report of two cases," Journal of Maxillofacial and Oral Surgery, vol. 8, no. 3, pp. 298-300, 2009.

[18] J.-L. Ribeiro, F.-H. Costa, E. K. Ana-Sueli-Rodrigues Cavalcante, Y.-R. Carvalho, and A.-L. Anbinder, "Vascular leiomyoma in the oral cavity-report of two cases," Journal of Clinical and Experimental Dentistry, vol. 11, no. 6, article e582, 2019.

[19] H. McParland, S. Warnakulasuriya, and R. J. Cook, "Angioleiomyoma: an unusual diagnosis for a lump in the cheek," British Journal of Oral and Maxillofacial Surgery, vol. 47, no. 8, pp. 641-642, 2009.

[20] E. Manor, N. Sion-Vardy, M. Nash, and L. Bodner, “Angiomyoma of buccal vestibule: a rare case with a normal karyotype," The Journal of Laryngology \& Otology, vol. 121, no. 12, pp. 1210-1212, 2007.

[21] K. A. Eley, S. Alroyayamina, S. J. Golding, R. N. Tiam, and S. R. Watt-Smith, "Angioleiomyoma of the hard palate: report of a case and review of the literature and magnetic resonance imaging findings of this rare entity," Oral Surgery, Oral Medicine, Oral Pathology and Oral Radiology, vol. 114, no. 2, pp. e45e49, 2012.

[22] S. Y. Rawal and Y. B. Rawal, "Angioleiomyoma (vascular leiomyoma) of the oral cavity," Head and Neck Pathology, vol. 12, no. 1, pp. 123-126, 2018.

[23] M. Pandya, D. S. Rao, G. Mamatha, and R. G. Annigeri, "Angiomyoma-a requisite in differential diagnosis of palatal growths," International Journal of Health Sciences, vol. 13, no. 6, p. 47, 2019.

[24] H.-Y. Kim, S.-N. Jung, H. Kwon, W.-I. Sohn, and S.-H. Moon, "Angiomyoma in the buccal space," Journal of Craniofacial Surgery, vol. 21, no. 5, pp. 1634-1635, 2010.

[25] C. F. W. Nonaka, K. M. A. Pereira, and M. C. D. C. Miguel, "Oral vascular leiomyoma with extensive calcification areas," Brazilian Journal of Otorhinolaryngology, vol. 76, no. 4, p. $539,2010$.

[26] F. Ide, K. Mishima, and I. Saito, "Angiomyoma in the submandibular gland: a rare location for a ubiquitous tumour," The Journal of Laryngology \& Otology, vol. 117, no. 12, pp. 10011002, 2003.

[27] T. M. Yoon, H. C. Yang, Y.-D. Choi, D. H. Lee, J. K. Lee, and S. C. Lim, "Vascular leiomyoma in the head and neck region: 11 years experience in one institution," Clinical and Experimental Otorhinolaryngology, vol. 6, no. 3, pp. 171-175, 2013.
[28] P. M. Som and H. D. Curtin, Head and Neck Imaging E-Book, Elsevier Health Sciences, 2011.

[29] C. Whittle, A. Retamal, D. Kramer, and C. Silva, "Sonographic diagnosis of periorbital dermoid cyst," Ultrasound Quarterly, vol. 33, no. 1, pp. 37-40, 2017.

[30] G. E. Anastassov and P. A. van Damme, "Angioleiomyoma of the upper lip: report of a case," International Journal of Oral and Maxillofacial Surgery, vol. 24, pp. 301-302, 1995.

[31] J. K. Brooks, N. G. Nikitakis, N. J. Goodman, and B. A. Levy, "Clinicopathologic characterization of oral angioleiomyomas," Oral Surgery, Oral Medicine, Oral Pathology, Oral Radiology, and Endodontology, vol. 94, no. 2, pp. 221-227, 2002.

[32] A. Giudice, F. Bennardo, C. Buffone, Y. Brancaccio, F. M. Plutino, and L. Fortunato, "Clinical and immunohistochemical features of oral angioleiomyoma: a comprehensive review of the literature and report of a case in a young patient," Case Reports in Dentistry, vol. 2019, Article ID 2498353, 9 pages, 2019. 